artigo ] voLume 10 | NÚMERO 21 | MAIO 2017

[JOÃO DALLA ROSA JÚNIOR]

Doutorando no programa de pós-graduação em Design da PUC-

Rio; docente na Faculdade SENAI CETIOT (RJ).

E-mail: joaodrjr@yahoo.com.br

\title{
A imagem de moda e a fotografia: justificativas a despeito da imagem em movimento
}

Fashion image and photography: some

[s8] considerations despite of the moving image

[resumo] Neste artigo, são propostas algumas justificativas acerca da predileção do campo da moda pela imagem fotográfica. A partir da constatação dos recursos tecnológicos disponiveis nas mídias sociais, como o Facebook e o Instagram, realiza-se uma comparação entre a imagem em movimento e a fixa. Assim, destacam-se as particularidades da preferência da moda pela fotografia, principalmente, com base nas considerações de Roland Barthes, em A câmara clara.

[palavras-chave

imagem de moda; fotografia; imagem em movimento.

[abstract] In this article, we propose some explanationsabout the predilection of the fashion field for photography. The text makes a comparison between the moving image and the still image from the observation of the technological resources available through digital media, such as Facebookand Instagram. Thus, the characteristics of the preference of fashion for photography are highlighted mainly from the considerations of the book Camera Lucida by Roland Barthes.

[keywords] fashion image; photography; moving image. 
No contexto da internet, os sitesde redes sociais podem ser considerados como espaços nos quais se encontram imagens. As redes, no âmbito geográfico, representam a velocidade e a diluição das fronteiras da informação em um mundo globalizado. De um modo geral, promovem uma descentralização da informação e, para as empresas, em especial para as marcas de moda, uma possibilidade de monitoramento do mercado consumidor, já que há um enfoque quantitativo da informação pela maneira como ela circula entre os agentes e é reproduzida em seus perfis, o que, na linguagem digital, é identificado pelo verbo compartilhar. Um ponto de destaque é que as redes sociais possuem um vínculo entre elas. 0 conteúdo migra de uma plataforma para outra por meio de recursos muito simples para o usuário, o que facilita ainda mais a reverberação de qualquer mensagem.

Entre os diferentes exemplos que a tecnologia associada à internet tem oferecido ${ }^{1}$, podemos destacar o Facebook, pois ele está entre as principais redes sociais, se não for a principal, por ter maior adesão de usuários. Nele, fotografias e vídeos podem ser postados em perfis pessoais ou em páginas institucionais, deixando a critério do usuário a melhor forma para registrar o conteúdo. Embora também seja caracterizado como um espaço de debate, um fórum, o que ganha evidência é a possibilidade da postagem da informação e a indexação do conteúdo, que, geralmente, está associado às marcações de lugares e/ou pessoas. No entanto, mais do que o Facebook, o Instagram parece ocupar lugar de destaque entre as redes que a comunicação de moda emprega. Como no caso acima, o Instagram permite a customização do perfil do usuário, porém ele não cria distinção entre um perfil mais institucional e outro pessoal. A indexação ocorre pelo uso de uma hashtag: expressões verbais compostas por palavras-chave antecedidas pelo simbolo cerquilha (\#). As hashtags tornam-se hiperlinks na internet, passiveis de serem rastreadas pelos mecanismos de busca, permitindo o acesso de outros usuários ao conteúdo selecionado.

0 foco do Instagram é a postagem de arquivos visuais, isto é, de imagens. Diferentemente, por exemplo, do Twitter, em que há ênfase no conteúdo verbal, o Instagram permite a publicação de imagens fixas ou móveis, com recursos de áudio. As imagens podem ser acompanhadas de legendas e o que o sistema da rede favorece é a criação de um banco de imagens associado ao perfil do usuário, independentemente de serem fotografias ou vídeos.

Em relação aos meios de comunicação, é necessário esclarecer o jogo entre termos quando mencionamos a palavra mídia. Conforme as considerações de Hans Belting (2011), as palavras media e medium referem-se ao meio material no qual uma imagem imaterial é fixada. Para o campo da comunicação, as mídias configuram-se como os veículos ou os canais pelos quais as mensagens são transmitidas e assumem o papel de "mediação entre uma ou mais realidade que 'retomam', contam e reproduzem, de um lado, e os usuários que desfrutam desse tipo de narratividade da realidade, de outro" (MASCIO, 2008, p. 170). Isto é, as mídias são os meios de comunicação que se apresentam como mediadoras das relações sociais e produtoras de sentido.

0 que nomeamos por mídias sociais alude aos meios que se contrapõem ao tradicionais, como jornal, televisão e rádio. Elas se caracterizam pela interação entre as pessoas na construção do conteúdo e pela infinitude de sua abrangência.As mídias sociais incluem as redes sociais como uma forma de tecnologia cujo foco é a comunicação. Conforme aponta Elman (2016), as mídias necessitam de suportes materiais que viabilizam o acesso ao conteúdo da informação. No caso das mídias sociais, a materialidade é expressa pelos dispositivos, como computadores e smartphones, que possibilitam o ingresso às redes sociais por meio da instalação de aplicativos nos aparelhos. Assim, há uma sobreposição de significados quando mencionamos o termo mídias sociais. A expressão pode aludir aos meios de 
comunicação oriundos dos avanços tecnológicos promovidos pela internet, mas também se referir ao meio material de fixação de uma imagem. Todas as redes citadas acima (Facebook, Instagram e Twitter) são mídias pelas quais circulam imagens. Portanto, indiretamente, indicam um meio eletrônico que materializa a imagem, ou seja, que fornece acesso à própria mídia.

De acordo com Schmitz (2013), no campo de estudos da comunicação, define-se midiatização como um processo pelo qual os meios de comunicação ganham papel de destaque na mediação social, principalmente pela forte atuação das empresas de produção de conteúdo. 0 processo de midiatização intensificou-se a partir da segunda metade do século XX e, hoje, tem se mostrado indispensável para a compreensão da sociedade. Ao que se refere à relação entre moda e mídia, é preciso "considerar a penetração dos meios de comunicação na vida em sociedade e refletir sobre como o campo da moda participa, mobiliza e se insere neste processo de midiatização" (SCHMITZ, 2013, p. 2).

É importante observar que o recorte temporal indicado pelo fenômeno da midiatização coincide com aquele nomeado por Barthes (2005, p. 65) como "civilização da imagem", ou seja, o período, a partir da década de 1960, no qual os meios de comunicação passaram a projetar a disseminação das informações por meio de composições que exploram as propriedades de fusão entre texto e imagens. A diferença que se percebe em relação ao século XXI é que, atualmente, vivemos, ao mesmo tempo, entre mídias tradicionais, como jornais, televisão, rádio e revistas, e sociais, como blogs, redes sociais, canais de vídeos ${ }^{2}$ e jogos eletrônicos. As mídias sociais têm se mostrado mais presentes em alguns campos, como é o caso da moda, e, com isso, nota-se inclusive a migração de alguns produtos dos meios tradicionais para os digitais. A maioria das revistas de moda apresenta-se, atualmente, nos dois suportes: o impresso e o digital. Não obstante, algumas publicações optam por expandir sua forma de comunicação por diferentes meios digitais, já que eles proporcionam maior dinâmica na circulação das mensagens.

A partir desta introdução, o ponto que quero destacar neste texto é que, apesar dos avanços tecnológicos que as mídias sociais promovem na circulação da imagem em movimento, a fotografia ainda corresponde a um padrão visual para a imagem de moda. Esta afirmação surge como resposta para uma provocação que me foi feita durante a minha pesquisa de doutoramento acerca do papel dos aplicativos que a comunicação de moda tem empregado uma vez que, na minha perspectiva sobre a imagem de moda, há uma ênfase na fotografia como um artefato que sobrevive aos avanços tecnológicos da imagem em movimento. Dessa forma, o presente texto nasce da necessidade de apresentação de argumentos sobre a predileção da moda pela fotografia, tendo em vista a construção de justificativas que possam ser colocadas em debate por meio da leitura de outros pesquisadores.

Para esclarecer o contexto da provocação, gostaria de adiantar que, grosso modo, minha pesquisa de doutoramento (ROSA JÚNIOR, 2017) versa sobre aquilo que eu chamo de um habitus visual do campo da moda. A partir da apropriação do conceito de habitus de Pierre Bourdieu (1996), que designa os condicionamentos posturais e comportamentais incorporados pelos agentes para o convívio dentro do campo social da moda, associo os aspectos da percepção visual que se referem aos condicionamentos sensiveis do olhar. A concepção panorâmica do conceito que proponho me leva a abranger os diferentes níveis da dimensão visual propostos por Meneses (2005) ao demarcar possíveis quadros referenciais para as disciplinas que abordam a visualidade como objeto de pesquisa. Assim, o habitus visual compreende como objeto a visão, através do papel subjetivo do observador, isto é, a qualidade do olhar do sujeito; o visivel, no que se refere à ação do poder e, dessa forma, a criação de regimes escópicos; e, por fim, o visual que se estabelece pelo conjunto de imagens como artefatos, cujos consumo, produção e circulação relacionam-se às características formais das imagens. 
Metodologicamente, o trabalho que realizo se insere nos estudos da Cultura Visual porque, em primeiro lugar, engloba os objetos e 0 olhar sobre eles (CHARRÉU, 2011). Em segundo lugar, porque estabelece como preceito o fato dos processos de ensino e aprendizagem exercerem papel fundamental na constituição do habitus social. Ou seja, a educação corresponde a um lugar privilegiado para a observação da formação do olhar uma vez que organiza, disciplinarmente, conteúdos e provoca experiências que se tornam os modelos das possibilidades de ação dos sujeitos (HERNÁNDEZ, 2011). Assim, na pesquisa de campo que o projeto envolve, disponho da minha experiência docente como meio para articular as questões da pesquisa e convido os alunos a participarem como colaboradores na produção e na coleta de dados ${ }^{3}$, assumindo um dos preceitos metodológicos que a Cultura Visual institui: as pesquisas se realizam com e sobre imagens ${ }^{4}$.

0 assunto referente à imagem em movimento impôs-se porque a maioria dos exemplos apresentados ao longo do meu trabalho de pesquisa ser oriunda das práticas fotográficas $\mathrm{e}$, em nenhum momento, fazer alusão aos novos aplicativos, principalmente, àqueles que permitem recursos de vídeos e áudios, como é o caso do Instagram e do Snapchat. Dessa forma, a seguinte questão torna-se premente: o que é inerente à fotografia para que ela assuma um lugar de destaque na comunicação de moda?

Para começar a expor as justificativas, gostaria de destacar que algumas delas são de ordem prática - envolvem contextos específicos sobre difusão tecnológica - e outras são de cunho teórico. Apesar da consonância entre as justificativas, vou me concentrar naquelas que estabelecem uma diferença epistemológica entre a imagem fixa e a em movimento, recorrendo, em especial, às considerações de Roland Barthes (1984) acerca da comparação entre fotografia e cinema. Um dos pontos, neste debate, se estabelece pela consideração de que a tecnologia das mídias sociais poderia modificar o suporte das imagens apresentadas pela comunicação. A intenção é que as justificativas genéricas se associem a considerações especificas sobre o campo da moda, de modo que seja possivel perceber como a imagem de moda apresenta algumas particularidades em relação aos campos da produção cultural e, em específico, àqueles que se destinam à criação e à circulação de imagens.

Em primeiro lugar, apesar de todas as redes sociais citadas acima serem disponiveis para aparelhos celulares ou tablets, que são os principais dispositivos para o funcionamento desses programas e hoje são os produtos que quase todos carregam consigo, elas não correspondem a uma homogeneidade na adesão do consumidor de marcas de moda. Sabe-se que há uma diferença concreta entre o perfil que a marca diz ser o do seu público-alvo e o das pessoas que realmente compram as roupas e as usam de acordo com o estilo da marca. Conforme aponta Las Casas (1993), a noção de alvo está associada ao mercado e tem em vista a seleção de pessoas que se quer atingir indiscriminadamente com os programas de marketing. No entanto, público consumidor refere-se àquele que usufrui o produto. Ele é determinado pelo processo de segmentação do mercado e é composto por diferentes grupos de pessoas, de acordo com as características de gênero, faixa etária, localização geográfica e poder aquisitivo, entre outras. Dessa forma, o que parece acontecer no caso do uso das tecnologias digitais é que, quando assumimos a posição de certa unanimidade de acesso aos aplicativos e, logo, ao tipo de imagem que eles proporcionam, estamos nos encaminhando para uma generalidade que não ocorre nos processos de comunicação de moda.

Muitas vezes, as marcas da indústria da moda configuram um perfil de público-alvo que, na verdade, nada mais é do que uma descrição de um jovem extremamente conectado aos recursos tecnológicos de comunicação e familiarizado com os conteúdos das mídias. Essas caracteristicas, por exemplo, podem ser encontradas nas representações geracionais realizadas pelas empresas de pesquisa 
de consumo, como são as descritas por Morace (2012). Pelo estudo do sociólogo, por exemplo, verifica-se que há uma diversidade de públicos e que o jovem, na verdade, se enquadra em um grupo de pessoas que tem entre 18 e 30 anos, chamados de Linker People. Eles são "filhos da nova social democracia" (MORACE, 2012, p. 55), seus valores se pautam pela individualidade e possuem forte participação nos fenômenos midiáticos e tecnológicos. Ou seja, representam uma parcela da população e, provavelmente, não são unanimidade entre o público consumidor de vestuário. No campo da moda, essa descrição está associada ao grupo fashion e, de certa forma, passa a indicar agentes que atuam no próprio meio ou em áreas correlatas. Portanto, a generalização do acesso aos dispositivos e do uso das redes sociais para a comunicação de moda, na verdade, corresponde à adoção da atitude por uma pequena parcela de pessoas do campo da moda, como índice da diversidade dos perfis de consumo que uma marca atinge.

Analisando a generalização por outra perspectiva, o que podemos considerar é que não são os meios que são compartilhados pela diversidade de pessoas, mas a noção que os precede. Susan Sontag (2004) afirma que a fotografia se estabelece como uma informação em nossa sociedade porque ela está presente em diferentes instâncias da vida cotidiana, inclusive, como recurso de outras ciências para além daquelas consagradas pela análise da imagem, como é o caso da História da Arte. Como informação, a fotografia se oferece a "esquemas de classificação e de armazenamento" (SONTAG, 2004, p. 172) e, por isso, passa a compreender uma referência para a qualificação de coisas reais. Basta lembrar o exemplo de quando vemos uma paisagem e identificamos a experiência com a expressão parece uma fotografia.

Mitchell $(2012$, p. 23) vai além do que se refere à nossa percepção sobre as imagens. Ele declara que uma das diferenças no deslocamento temporal possivel de se traçar na história da relação do homem com a imagem é que "na imagem primitiva, somos nós [os homens] que desejamos matar o objeto selvagem representado; na imagem contemporânea e futurista, o objeto artificial criado por nós tornou-se selvagem e ameaça nos matar". Apesar de Mitchell mencionar a diferença sobre a questão da representação animal na Caverna de Lascaux e no filme Jurassic Park, podemos transferi-la à sugestão do sentimento de ameaça que as imagens têm provocado nos indivíduos em nossa sociedade. A sensação de emergência que as redes sociais criam em relação à publicação de imagens faz com que elas se sobreponham à própria experiência do olhar. Parece que o desafio da Esfinge se tornou: Fotografe-me ou te devoro.

Em segundo lugar, indico uma justificativa bastante pragmática. A produção de um vídeo em comparação à de uma fotografia é muito onerosa para os orçamentos apertados das marcas e dos canais de comunicação de moda. Quando vemos os créditos de um filme, percebemos o número de pessoas comprometidas com as tarefas que a imagem em movimento exige. Em sua noção coletiva de trabalho, Howard Becker (2010, p. 32) comenta que, mesmo com o registro da listagem de créditos, o número real de pessoas envolvidas na produção de um filme é sempre maior do que aquilo que aparece na tela, pois a cadeia de atividades está relacionada à divisão social do trabalho. No caso de um vídeo de moda, podemos pensar que teríamos o mesmo número de agentes que normalmente estão nas produções das campanhas publicitárias: fotógrafos, produtores, modelos, cabeleireiros, maquiadores, entre outros. No entanto, na fase de edição, enquanto um número menor de profissionais resolveria o tratamento das fotografias, em um filme, a quantidade se expande graças às especificidades dos recursos de áudio e também da própria imagem. Além disso, lembremo-nos de que muitas tomadas são necessárias para se produzir o material bruto de construção de um vídeo. Algumas vezes, são horas de filmagem para apenas um minuto de imagem. Em 
uma pergunta, podemos ter uma noção quantitativa desse trabalho: quantas vezes uma imagem fixa existe em uma imagem em movimento? Basta rememorar a experiência do bloco de papel no qual desenhos são realizados em sequência e provocam a sensação de movimento durante a ação de folheá-lo rapidamente.

0 que quero dizer é que a imagem em movimento multiplica a imagem fixa e, com isso, as condições de sua produção também são graduadas. Os meios de comunicação e as marcas controlam os gastos com publicidade. Embora as tecnologias permitam que vídeos sejam difundidos nas redes sociais, a imagem institucional não se restringe a um simples registro fílmico de um desfile. Dessa forma, a imagem em movimento representa um alto investimento e deve ser aplicado com precisão para garantir o retorno à altura da expectativa.

Em terceiro lugar, há a justificativa epistemológica. Ela se apoia em três pontos específicos que Roland Barthes (1984) destacou na comparação entre a fotografia e o cinema, a saber: o tempo, a pose e a morte. É possível perceber que todos os pontos se associam a uma mesma perspectiva que está evidente nas análises de Barthes desde a publicação do livro Mitologias, conforme aponta Motta (2014). A perspectiva refere-se ao modo como a imagem fotográfica se estabelece por um viés mítico, o que para Barthes significa a dimensão retórica do signo perante a produção massiva da indústria cultural. Como a moda também se evidencia como um sistema retórico e, portanto, mítico para Barthes (1979), percebo que as considerações sobre as fotografias se aplicam à abordagem da relação entre moda e imagem presente nas práticas do campo social da moda e, principalmente, na constituição do habitus visual dos agentes.

Acerca do tempo, o que é particular à fotografia é que ela se torna uma evidência do passado: o referente esteve em frente à máquina fotográfica. Como Barthes diz, ela atesta que "o que eu vejo de fato existiu" (1984, p. 123), isto é, "a essência da Fotografia consiste em ratificar o que ela representa" (1984, p. 128). Desde as invenções do século $\mathrm{XIX}$, cujos processos físico-químicos deram origem ao registro da imagem sobre algum suporte através da câmera, o tempo passou a ser imobilizado e fixado pela ação do obturador. 0 cinema, que é o maior exemplo da imagem em movimento, apesar de se constituir de material fotográfico, não permite a fixação do tempo sobre o referente. 0 objeto para a imagem em movimento acompanha a passagem do tempo e projeta a sensação de futuro ao espectador. Ao contrário, "ela [a fotografia] é desprovida de futuro" (BARTHES, 1984, p. 134), pois se relaciona ao passado e permite a autenticação do que aconteceu no presente do espectador. Ou seja, sua imagem, apesar de atestar o passado do referente, é sempre presente para quem a observa.

No caso da comunicação de moda, a questão do tempo se apresenta pela necessidade de evidência das tendências de moda, através de registros de desfiles, editoriais presentes nas revistasou, até mesmo, de imagens de blogs, as fotografias de moda representam os lançamentos de estilos na lógica temporal da moda. Em outras palavras, elas indicam o que foi apresentado ou usado por alguém, em algum evento, na intenção de divulgar a dimensão presente da constatação. Nesse sentido, a imagem não representa o que está por vir, mas o que já é e foi capturado pela ação da fotografia.

Nesse caminho, a pose está associada ao tempo. Ela sintetiza o momento de fixação do corpo daquele que se pôs em frente à câmera. Diferentemente do cinema, em que o corpo parece passar pelo dispositivo, a fotografia congela o instante, demarcando nos traços corporais a condensação do tempo e a imobilidade do sujeito.

Na pose, são incorporadas as posições visuais dos agentes: "A do sujeito olhado e do sujeito que olha" (BARTHES, 1984, p. 22). Ou seja, por meio dela, estão codificadas as posições sociais e podemos perceber o condicionamento sensivel do corpo diante das estratégias visíveis dos mecanismos adotados pelo campo 
da comunicação de moda. Quando reconhecemos que há padrões corporais de representação na fotografia, estamos constatando a eficácia da imagem em determinar a pose do sujeito.

Barthes (1984, p. 164) comenta que a pose tem um poder de colocar em diálogo os olhares dos sujeitos, principalmente, quando é frontal. Embora ele mencione que essa posição seja arcaica para os retratos, ele diz que isso quase nunca acontece com o cinema: "No filme, ninguém jamais me olha". No entanto, a devolução do olhar do referente parece caracterizar com excelência a fotografia de moda. As modelos, na maioria das vezes, olham fixamente para a câmera e, quando a fotografia passa para a fruição do espectador, o que acontece é quase uma relação hipnótica. A troca de olhares conduz o efeito da fotografia a um resultado semelhante ao do ícone religioso (BARTHES, 1984). No campo da moda, podemos dizer que isso ocorre porque a fotografia provoca uma espécie de identificação, ou até mesmo idolatria do significante, o que Barthes (1979) demonstrou acontecer intensamente no sistema de moda escrito e na relação logo icônica da fotografia de moda nas revistas.

A ação mecânica da fotografia quebra a "camada mortifera da pose" (BARTHES, 1984, p. 30), pois, para o autor, o ruído da câmera corresponde ao barulho do tempo. Nesse sentido, eis o terceiro ponto. Podemos perceber que a morte se desdobra da relação temporal e corporal que as outras duas caracteristicas da fotografia indicam. Além disso, amplia o contexto de observação para o debate histórico, visto que associa os primórdios da fotografia no século XIX às mudanças nas práticas sociais que envolviam a morte.

Contemporânea do recuo dos ritos, a Fotografia corresponderia talvez à intrusão, em nossa sociedade moderna, de uma Morte assimbólica, fora da religião, fora do ritual, espécie de brusco mergulho na Morte literal. A Vida/a Morte: o paradigma reduz-se a um simples disparo, o que separa a pose inicial do papel final. (BARTHES, 1984, p. 138)

0 contexto de morte a que Barthes se refere pode ser associado à intensificação dos valores sociais do novo e da individualização que, principalmente a partir da modernidade, passaram a caracterizar a nossa sociedade e que foram amplamente comentados por Lipovetsky (1989). As tradições que promoviam a continuidade dos valores sociais e eram exemplares nos costumes religiosos e ritualísticos cederam espaço para os valores da sociedade industrial, cuja lógica opera a mudança social pela distinção dos bens de consumo. Não há a continuidade dos valores eternos e dogmáticos da cultura religiosa, mas há a mobilidade social que o giro do capital promove com a produção dos signos de distinção. Le Goff (2003) diz que no século XX, diante da crise do progresso, despontaram novas atitudes sobre as relações temporais.

A aceleração da história [...] levou as massas dos países industrializados a ligarem-se nostalgicamente às suas raízes: daí a moda retrô, o gosto pela história e pela arqueologia, o interesse pelo folclore, o entusiasmo pela fotografia, criadora de memórias e recordações, o prestígio da noção de patrimônio. (LE GOFF, 2003, p. 224)

Com isso, o sentido de morte se relaciona ao fato de a fotografia se tornar um instrumento de lembrança por imobilizar o tempo e o corpo em uma sociedade na qual tudo é passageiro. Pierre Nora indica que a modernidade criou um sentimento de "memória dever" (1993, p. 12), isto é, em meio às contínuas mudanças e ao 
contexto cada vez mais rápido de transformação social, ao sujeito moderno coube uma obrigação de memória individual, que "se apoia inteiramente sobre o que há de mais preciso no traço, mais material no vestígio, mais concreto no registro, mais visivel na imagem" (NORA, 1993, p. 14). Portanto, a morte a qual a fotografia alude está no sentido de fim demarcado na noção burguesa de vida, isto é, a obsolescência. Diferentemente do sentido de morte das religiões que acreditam na vida eterna, a sociedade industrial e capitalista atribui valor à matéria. A fotografia corresponde ao artefato de imagem que materializa o dever de memória.

Para exemplificar essas considerações, observa-se que o Instagram fornece um banco de imagens das publicações de seu usuário. Todas as imagens postadas ficam salvas no perfil da conta e são acessíveis aos demais integrantes da rede social. 0 próprio aplicativo diz que uma das operações que o usuário pode realizar consiste em "escolher um filtro para transformar a imagem em uma memória que se mantenha para sempre" (INSTAGRAM, 2016, tradução nossa). Nessa declaração, a eternidade está associada à imagem publicada. Ela garantirá a lembrança do momento vivido sobre a aparência de um filtro, que pode ainda dar à imagem mais cores de memória. 0 significado que o banco de imagens adquire em relação ao sentimento de um dever de memória é o que distingui, inclusive, o Instagram do Snapchat. A logo de fantasma que justamente representa a permanência do tempo não se concretiza no funcionamento do último aplicativo, cuja programação prevê no máximo 24 horas de sobrevivência para a imagem publicada.

No caso do campo da moda, a justificativa da predileção pela fotografia está na dose de eternidade que ela representa no presente da lógica fashion. Isto é, na moda, a imagem fotográfica está inserida em um campo no qual a passagem do tempo é muito definida. Como Barthes (1984, p. 139) sugere: "A fotografia é um testemunho seguro, mas fugaz". A segurança que ela emana é inversamente proporcional à rapidez com que a moda se refaz. A imagem em movimento demanda muito tempo para ser apreciada: com o movimento, não há estabilidade. Logo, a segurança da fotografia de moda está em sua imobilidade mais arcaica e frontal, o que Barthes (1984, p. 138) designa na qualidade de uma "morte chã".

À luz das ideias de Barthes, Marra (2008) sintetiza as considerações sobre a fotografia de moda, expondo que, na verdade, precisaríamos pensar também em um contexto que poderia ser chamado de "moda da fotografia" (MARRA, 2008, p. 47), pois não limitaríamos a fotografia a uma representação da moda, mas, sim, veríamos nela mais uma das experiências e dos significados que a moda abrange. Compartilhando dessa posição, Rainho (2014, p. 60) resume que "a fotografia de moda não é a mímese da moda, uma vez que ao propor uma determinada estética, ela cria a moda mesma". Com isso, os diferentes elementos que o campo da moda emprega - objetos do vestuário, imagens (fotografias, croquis etc.) e textos (propagandas, resenhas etc.) - compõem a diversidade de sentidos que ela ganha de acordo com os distintos grupos e agentes sociais envolvidos. 0 que há de semelhante entre os diferentes elementos são as "expectativas e convicções" (BERGAMO, 2007, p. 41) quanto à moda, atribuídas pelos agentes do campo.

Ainda sobre a consideração de uma "moda da fotografia", Marra (2008, p. 39) afirma que, para a compreensão da imagem de moda, são mais relevantes as contribuições oriundas de aportes teóricos sobre "a credibilidade do sonho, do poder do análogon, de indicialidade e de simulação expresso pela fotografia". Ele explica esses conceitos ao propor a expressão "como se" (MARRA, 2008, p. 37) para definir a função que a fotografia de moda cumpre perante as práticas do campo. 0 "como se" indica a artificialidade material do artefato fotográfico e a maneira pela qual ele submete o olhar do sujeito a experiências que colocam em jogo suas expectativas e convicções de moda. 0 sonho está relacionado às expectativas dos agentes; o análogon, à condição da fotografia de refratar a realidade vivida; a indicialidade apresenta-se pelo efeito da marca advinda da transposição física do 
referente da imagem; e a simulação se configura pela legitimidade da experiência que a fotografia proporciona diante dos debates sobre a categoria virtual que os avanços tecnológicos atribuiriam às imagens.

Um dos pontos de destaque da proposta de Marra - e que vai ao encontro da provocação que deu início a este texto - é o debate sobre a imagem digital no contexto dos avanços tecnológicos. Para o autor, a categoria "como se" também se aplica à imagem advinda das tecnologias e não estrutura uma diferença de uso entre as modalidades digitais e analógicas. Como sugere, "a indicialidade fotográfica, se corretamente entendida, nunca foi uma questão de película ou de pixel" (MARRA, 2008, p. 46). Isto é, embora os avanços tecnológicos permitam recursos de novos formatos de imagem, a predileção pela fotografia na comunicação de moda reside no modo como ela representa práticas sociais que estão estruturadas no campo da moda e que não se alteram na mesma velocidade com que a própria moda muda.

Dando continuidade ao pensamento de Marra, gostaria de ressaltar que a imagem de moda ainda é estática. Essa declaração se opõe ao texto de Nathalie Khan, no qual ela atesta que "a imagem de moda não é mais estática" (KHAN, 2012, p. 246, tradução nossa). Suas justificativas estão pautadas na difusão do que ela chama de "filmes digitais de moda" (KHAN, 2012, p. 238, tradução nossa) e tomam como exemplo a produção do website SHOWstudio, cuja direção é de Nick Knight e seu lançamento data de novembro do ano 2000.

Khan afirma que a imagem de moda não é mais estática porque os filmes digitais elaboram, por meio do movimento, uma temporalidade diferente daquela da fotografia e também porque capturam o corpo de uma maneira fragmentada, o que o torna um objeto de percepção. Três vídeos do projeto The Fashion Body, cuja organização é do SHOWstudio, são empregados para exemplificar esses argumentos, já que "cada sequência em movimento fetichiza o objeto a partir do corte, do movimento e do fluxo" (KHAN, 2012, p. 240, tradução nossa). Nos três vídeos, a autora diz que há um diálogo entre a imagem fixa e a imagem em movimento, já que a edição, o corte e a passagem de um quadro para outro provocam a percepção de movimento, fornecendo, assim, a sensação do tempo presente. Em suas palavras, "quando as imagens mudam abruptamente de uma para outra, 0 fluxo é interrompido e o senso de passagem do tempo é suspenso" (KHAN, 2012, p. 242, tradução nossa). Assim, a noção do presente é reforçada na temporalidade que a própria imagem cria pelo seu movimento.

0 argumento acima pode ser contraposto às considerações de Barthes e de Marra. Conforme os autores, a fotografia é a imagem do tempo presente. 0 vídeo, pelo movimento, implica a percepção da passagem do tempo. Além disso, como apontamos nas considerações de Marra, não é possível determinar que as tecnologias, associadas às mídias sociais, façam com que haja uma mudança no tipo da imagem que circula no campo da comunicação de moda. Khan deixa evidente que a fotografia ainda é uma referência para a produção dos vídeos, inclusive pela forma adotada nas edições e nos enquadramentos dos filmes. As disposições visuais não se alteram no mesmo ritmo das mudanças da moda, principalmente, porque mudanças envolvem riscos de produção e condições de acesso à tecnologia. Assim, talvez a indicação mais apropriada à afirmação de Khan seja não anular o papel da imagem estática. Considerar a permanência dessa característica é entender como uma imagem de moda alude ao que há de mais digital no campo, quando está publicada em uma rede social, como o Instagram, ao mesmo tempo em que apresenta o produto pelo que há de mais imóvel na representação do corpo: a fotografia.

Sintetizando os diferentes argumentos expostos até então, gostaria de finalizar dizendo que a imagem estática, como a fotografia, cumpre um papel peculiar 
no campo da moda. Embora possamos pensar que a imagem em movimento seja um recurso muito difundido na moda graças aos avanços tecnológicos que as mídias têm permitido empregar na comunicação, é necessário destacar que as instâncias de produção e circulação não acompanham a facilidade de visualização, principalmente no que se refere ao custo de produção de vídeos e ao acesso do público consumidor à tecnologia. Além disso, há um fundamento ideológico na predileção da fotografia na formação do habitus visual do campo da moda. Esse fundamento pode ser encontrado quando Barthes (1979) associa as práticas da moda ao teatro. Ele sugere que a fotografia desempenha uma função de representação da cena. Ou seja, o tempo, a pose e a morte estariam contextualizados no teatro que as mídias realizam para representar os significados de moda em nossa sociedade capitalista e industrial. A fotografia, assim, fixa o tempo presente da cena, convoca o corpo do sujeito e ressuscita o sentido de moda na própria lógica de suas constantes mortes anunciadas.

Para ilustrar essas considerações finais, gostaria de citar brevemente a abertura do último episódio da 8 a temporada do RuPaul's DragRace (2016), veiculada no mês de maio de 2016 pela LogoTV. Por ser tratar de um reality de competição entre drag queens, liderada pela legendária RuPaul, o programa mescla diferentes referências do mundo fashion e se torna um objeto de estudo sobre como 0 habitus visual da moda se difunde. No palco de um teatro com amplas cortinas, o episódio final contou com um anúncio de abertura e trouxe as ganhadoras das temporadas anteriores dispostas nas laterais da figura central de RuPaul, formando uma composição semelhante a uma fotografia de familia. Na imagem em movimento que o vídeo apresenta, vemos as cortinas se abrirem e o público ressoar em aplausos e urros. RuPaul, em meio àquela ovação, simplesmente diz: "I've got an ideia: why don't you take a picture? It'll last longer"'s.

Recebido em: 2/01/2017

Aprovado em: 23/02/2017 


\section{NOTAS}

${ }^{1}$ Neste texto, mencionaremos quatro redes sociais: Facebook, Twitter, Instagram e Snapchat. Elas podem ser contextualizadas em uma linha do tempo, pois representam o desenvolvimento das mídias no âmbito da internet. 0 Facebook teve seu lançamento em 2004 e ficou famoso pela atuação de seu criador, Mark Zuckerberg. 0 Twitter surgiu em 2006 e seu diferencial foi a concentração das funções da rede no envio e no recebimento de textos de até 140 caracteres, que passaram a ser conhecidos como tweets. Já o Instagram e Snapchat correspondem a redes mais recentes, criadas a partir de 2010, e se dedicam exclusivamente ao compartilhamento de imagens.

2 Os canais de vídeos se referem a plataformas como Youtube e Vimeo.

${ }^{3} 0$ trabalho de campo realizado durante a pesquisa caracterizou-se pela observação participante da turma da disciplina de Comunicação aplicada à Moda (2015/01), do curso de bacharelado em Design de Moda da Faculdade SENAI CETIQT (RJ). Por meio da interação entre os discentes e o docente, foram analisas as disposições visuais dos alunos sobre os conteúdos da disciplina e as imagens empregadas pelo campo da comunicação de moda.

${ }^{4}$ Apesar dessa consideração, neste artigo não lançarei mão de imagens pelo fato de o texto tratar da fotografia como uma categoria qualitativa de imagem, cujas caracteristicas permitem uma abordagem mais teórica do tema.

5 "Eu tive uma ideia: por que você não tira uma fotografia? Ela vai durar mais." (tradução nossa)

\section{REFERÊNCIAS}

BARTHES, Roland. A câmara clara: nota sobre a fotografia. Rio de Janeiro: Nova Fronteira, 1984.

.Inéditos, vol. 3: imagem e moda. São Paulo: Martins Fontes, 2005.

Sistema da moda. São Paulo: Ed. da Universidade de São Paulo, 1979.

BECKER, Howard S. Mundos da arte. Lisboa: Livros Horizontes, 2010.

BELTING, Hans. Introduction and an Anthropology of Images: Picture, Medium, Body. In: An Anthropology of Images. New Jersey: Princeton University Press, 2011, pp. 1-36.

BERGAMO, Alexandre. A experiência do status: roupa e moda na trama social. São Paulo: Editora UNESP, 2007.

BOURDIEU, Pierre. A gênese social do olho. In: As regras da arte: gênese e estrutura do campo literário. São Paulo: Companhia das Letras, 1996, pp. 348-356.

CHARRÉU, Leonardo. Cultura visual: rupturas com inércias e ignorâncias curriculares. In: MARTINS, Raimundo. TOURINHO, Irene. (Org.). Educação da cultura visual: conceitos e contextos. Santa Maria: Ed. da UFSM, 2011, pp. 113-128.

ELMAN, Débora. A revista de moda vaipara a rede: uma análisedas reportagens nolnstagram das revistas Elle e Estilo na SãoPaulo Fashion Week. Dobra[s], vol. 9, n. 19, pp. 137-145, 2016. Disponivel em: <https:// dobras.emnuvens.com.br/dobras/article/view/457/414>. Acesso em: 3 mar. 2017.

HERNÁNDEZ, Fernando. A cultura visual como um convite à deslocalização do olhar e ao reposicionamento do sujeito In:MARTINS, Raimundo. TOURINHO, Irene. (Org.). Educação da cultura visual: conceitos e contextos. Santa Maria: Ed. da UFSM, 2011, pp. 31-49.

INSTAGRAM. FAQ 2016. Disponivel em: <https://www.instagram.com/about/faq/>. Acesso em: 20 ago. 2016.

KHAN, Nathalie. Cutting the fashion body: why the fashion image is no longer still. Fashion Theory: The Journal of Dress, Body \& Culture, vol. 16, n. 2, pp. 235-250, 2012.

LAS CASAS, Alexandre Luzzi. Marketing: conceitos, exercícios, casos. São Paulo: Atlas, 1993.

LE GOFF, Jacques. História e memória. Campinas: Editora da Unicamp, 2003.

LIPOVETSKY, Gilles. 0 império do efêmero: a moda e seu destino nas sociedades modernas. São Paulo: Companhia das Letras, 1989.

MARRA, Claudio. Nas sombras de um sonho: história e linguagens da fotografia de moda. São Paulo: Editora Senac São Paulo, 2008.

MASCIO, Antonella. Moda e meios de comunicação de massa. In: SORCINELL, Paolo. Estudar a moda: corpos, vestuários, estratégias. São Paulo: Editora Senac São Paulo, 2008, pp. 169-176.

MENESES, Ulpiano T. Bezerra de. Rumo a uma história visual. In: MARTINS, José de Souza; ECKERT, Cornéliact NOVAES, Sylvia Caiuby. (Org.). 0 imaginário e o poético nas ciências sociais. 1a.ed.: EDUSC, 2005,pp. 33-56. 
artigo ] JOÃO DALLA ROSA JÚNIOR

MITCHELL W. J. T. O futuro da imagem: a estrada não trilhada de Rancière In: MARTINS, Raimundo.

TOURINHO, Irene. (Org.). Cultura das imagens: desafios para a arte e para a educação. Santa Maria: Ed. da UFSM, 2012, pp. 19-35.

MORACE, Francesco. Consumo autoral: as gerações como empresas criativas. São Paulo: Estação das Letras e Cores Editora, 2012

MOTTA, Leda Tenório da.Imagens que machucam. Notas sobre a poética da fotografia em Roland Barthes. Paralaxe, Revista de estética e filosofia da arte, Ano II, N. Especial, Programa de Estudos Pós-graduados em Filosofia - PUC/SP, 2014, pp. 20-29.

NORA, Pierre. Entre memória e história: a problemática dos lugares. Revista Projeto História. São Paulo, n. 10, pp. 7-28, dez. 1993.

RAINHO, Maria do Carmo Teixeira. Moda e revolução nos anos 1960. Rio de Janeiro: Contra Capa, 2014

ROSA JÚNIOR, João Dalla. Imagem e moda: um estudo sobre o habitus visual. Rio de Janeiro, 2017. Tese de Doutorado (Doutorado em Design) - Departamento de Artes e Design, Pontificia Universidade Católica do Rio de Janeiro, 2017.

RUPAUL'S DRAG RACE. Season 8, Gag Worthy Finale Opening. Produção da LogoTV. Disponivel em: <https://www.youtube.com/watch?v=0KV-P-mAxWE>. Acesso em: 29 maio 2016.

SCHMITZ, Daniela. Moda e midiatização: aproximações e tensionamento. In: Colóquio de Moda 11, 2015, Curitiba. Anais eletrônicos. Disponivel em: $<$ http://www.coloquiomoda.com.br/anais/anais/11-Coloquiode-Moda_2015/ARTIGOS-DE-GT/GT07-MODA-E-MIDIA/GT-7-MODA-E-MIDIATIZACAO.pdf . Acesso em: 19 ago. 2016, pp. 1-12

SONTAG, Susan. Sobre fotografia. São Paulo: Companhia das Letras, 2004. 